\title{
Multivariate Optimization of PMBOK, Version 6 Project Process Relevance
}

\author{
Philipp Rosenberger ${ }^{1}$ and József Tick ${ }^{2}$ \\ ${ }^{1}$ University of Applied Science FH Campus Wien, Favoritenstrasse 226, 1100 \\ Vienna, Austria, philipp.rosenberger@fh-campuswien.ac.at \\ ${ }^{2}$ Óbuda University, Bécsi út 96/b, 1034 Budapest, Hungary, tick@uni-obuda.hu
}

\begin{abstract}
This article examines the use of multivariate optimization, as a method, to improve the success of project management tasks. The optimization approach is founded on 8 selected continuous project processes of the execution phase of the PMBOK project management framework. Using a custom-developed, online portal, 103 data sets were collected from project management practitioners, indicating their individual distribution of effort and focus on the selected project processes, as well as, the current health status of their project. Based on this dataset, stepwise regression combined with optimization applying a sequential quadratic programming method was used to define the distribution of project process relevance thereby maximizing the project health.
\end{abstract}

Keywords: Process Optimization; Multivariate Optimization; Project Management; PMBOK

\section{Introduction}

Managing a project involves a versatile approach and related skillsets. Although every project is said to be different and unique, project management frameworks like the project management body of knowledge (PMBOK) [1], ICB4 of the International Project Management Association [2], or PRINCE2 framework of Axelos [3] push towards a standardized project management approach by providing certifications and guidelines on how to act as a successful project manager. The basic question underlying this research article is the field of tension between a rigid standardized guideline and framework of how to manage a project and the uniqueness of projects and the individuality of project managers.

Project management frameworks provide different guidelines on how to successfully manage a project. They do not indicate the scope of the different tasks. This situation provides freedom for experienced project managers, but at the same time it can make decisions harder for unexperienced project managers [4], 
particularly in agile managed IT projects [5]. The fact that decisions are challenging for project managers is also highlighted by the Chaos Report [6] detailing that IT projects only have success rates between $11 \%$ in case of waterfall development and $39 \%$ in case of agile development.

\section{Definitions based on Literature Review}

This research uses mathematical methods of multivariate regression and optimization as an attempt to define the most successful way of managing different kinds of projects. In contrast to a dynamic modeling and optimization of project processes based on ER methodologies as described by Kukushkin and Zykov [7], the optimization relies on collected data of project management practitioners. However, before describing in detail how these methods are used, several definitions and terms need to be explained:

\section{Project Process}

PMBOK as a project management framework defines in its sixth version 49 project processes. These processes are tasks and activities a project manager has to perform and cover in his or her daily work, such as doing a risk analysis with sophisticated approaches like fuzzy [8] or PRISM [9] based decision-making methods, controlling the budget or keeping the stakeholders engaged. In other words, project processes can be seen as a toolbox of activities a project manager can choose from.

\section{Project Process Relevance}

The hypothesis underlying the present research claims, that project managers may decide individually how much focus and time they devote to certain project processes. The amount of focus and time a project manager puts into a certain project process is defined as "project process relevance" is in this research. Using such an approach, business process management (BPM) practices [10] can be applied. The project manager then also covers the role of a process analyst [11] being responsible for monitoring, measuring and optimizing his or her own way of working [12].

\section{Project Process Relevance Distribution}

Project process relevance distributions are the input of the multivariate optimization. In the survey, project managers are asked to distribute their individual project process relevance in a specific project of their choosing. As a project is structured in phases, starting at the initiation phase and ending at the closing phase, not all 49 project processes defined in the PMBOK are relevant at the same time. This research shall only act as a proof of concept and therefore, 
only uses continuous project processes of the execution phase. The advantage of this restriction is a drastic reduction of complexity in the optimization.

\section{Project Health Factors}

Project Health Factors are used as the output side of the optimization, measuring the current "health" of a project. The term "success" of a project is not used, because a lot of the datasets are related to ongoing projects, which have not achieved success yet. However, project managers can often provide an indication of the current status regarding budget, scope, schedule and people [13] or more specific, customer satisfaction. Combing these four project health factors to one single output value provides the necessary output side of the optimization. The approach of converting multiple responses to a single response is based on the idea described by Khuri and Conlon [14]. However, a complex vector-distance based model did not seem necessary for the simple goal of combining result variables. Consequently, a amalgamation approach, as in signal noise ratio research [15], was selected. Constrained optimization, defining one single output factor as leading and the others as constraints [16] is not used, because all project health factors are considered equally important for overall project success.

\section{Methodology}

\subsection{Definition of Optimization Focus}

To prove that multivariate optimization can be used to optimize the way project managers work, a project management framework was chosen. PMBOK by PMI organization is, with over 500,000 members [17] and its focus on clear tasks, documentation and processes [18], the chosen framework for this research rather than soft skill-related activities that are hard to evaluate.

As many of the survey participants are currently working in a specific project, a project phase was selected. Although planning as a phase is mentioned as a critical success factor [19], the execution phase, which can have quite a long duration comprising the bulk of the project work [20], was selected for this research. The execution phase contains 10 processes, 8 of which are continuous processes, and the scope of the optimization approach.

Below a brief description of continuous processes and their ID of the selected execution phase can be seen [1]:

- $\quad$ P1 = Direct and Manage Project Work - the process of leading and performing the work defined in the project management plan and implementing approved changes to achieve the project objectives. 
- $\quad$ P2 = Manage Project Knowledge - the process of using existing knowledge and creating new knowledge to achieve the project objectives and contribute to organizational learning.

- $\mathbf{P 3}=$ Manage Quality - the process of translating the quality management plan into executable quality activities that incorporate the organization's quality policies into the project.

- $\quad$ P4 = Develop Team - the process of improving competencies, team member interaction, and overall team environment to enhance project performance.

- $\quad$ P5 = Manage Team - the process of tracking team member performance, providing feedback, resolving issues, and managing team changes to optimize project performance.

- $\quad$ P6 = Manage Communications - the process of ensuring timely and appropriate collection, creation, distribution, storage, retrieval, management, monitoring, and the ultimate disposition of project information.

- $\quad$ P7 = Implement Risk Responses - the process of implementing agreedupon risk response plans.

- $\quad$ P8 = Manage Stakeholder Engagement - the process of communicating and working with stakeholders to meet their needs and expectations, address issues, and foster appropriate stakeholder involvement.

Four project health factors have been selected as the optimization output. The classical project success triangle of budget, scope and schedule [21] has been enriched based on the concept of van Wyngaard et al. [22] with an additional factor of customer satisfaction, since especially in IT projects high customer satisfaction and resulting project success are possible even without keeping the initially defined scope, budget or schedule.

\subsection{Sampling Procedures}

Sample selection was performed by disseminating the invitation for participation of project management practitioners on social networks like LinkedIn or Facebook, sending emails to a network of former Technical Management students at the UAS "FH Campus Wien" in Vienna and addressing suitable participants directly in networking events and conferences. All persons previously or currently involved in project management in different roles were able to participate. An estimated number of 600 invitiations sent over a period of 18 months, led to 103 actual and valid, survey completions. 
Additionally, current students at the involved universities (Vienna/Budapest) with previous work experience in those fields were invited to participate even if they did not work in management; basic knowledge of project work and PMI project processes was sufficient. This ensured that participants with various levels of experience were included in the study, thus allowing candidates with different perceptions of project management to contribute to ensure a wide variety of insights.

\subsection{Questionaire Design}

The actual data collection was implemented using a custom-programmed data collection cloud-based web portal [23], since out of the box survey software solutions did not provide the specific capability of distributing relevance factors.

Link: https://agile-projects-survey.herokuapp.com/home

Besides distributing project process relevance distributions as the input parameter and project health factors as the output parameter, the survey participants also entered characteristics of their background and projects. These additional characteristics are not interpreted in the research results as such, other than in the following chapter summarizing the respondents' characteristics.

\subsection{Respondents}

Of the 103 people who answered the survey, $73 \%$ are male, $27 \%$ are female. $45 \%$ of the participants are aged between 20 and 30 years, 33\% between 30 and 40 years and the remaining participants are of older age. A majority of 86 people has completed university education, and half of the participants $(51 \%)$ are experienced as project managers or project sponsors. Most participants (51\%) work in Management and Business, IT and Financial related industries.

$52 \%$ of the participants work with agile [24] or at least hybrid [25] project management frameworks.

\subsection{Initial Statistical Analysis}

A basic statistical analysis of the input and output factors resulted in below average and standard deviation results: 


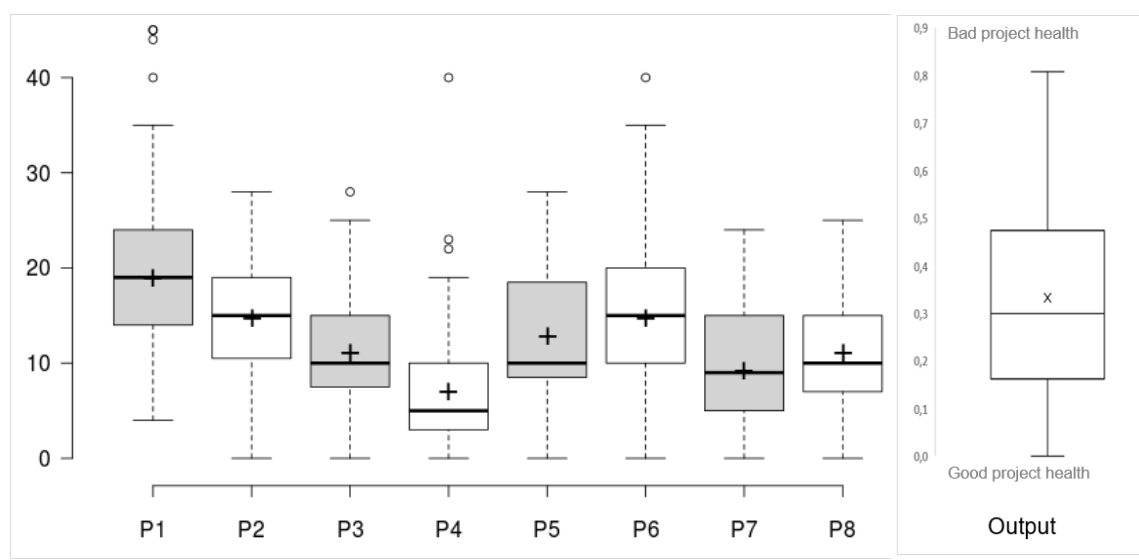

Figure 1

Box Plot Statistics

Source: self-edited

Table 1

Box Plot Statistics

\begin{tabular}{|c|c|c|c|c|c|c|c|c|c|}
\hline & P1 & P2 & P3 & P4 & P5 & P6 & P7 & P8 & Output \\
\hline $\begin{array}{c}\text { Upper } \\
\text { whisker }\end{array}$ & 35.00 & 28.00 & 25.00 & 19.00 & 28.00 & 35.00 & 24.00 & 25.00 & 9.00 \\
\hline $\mathbf{3}^{\text {rd }}$ quartile & 24.00 & 19.00 & 15.00 & 10.00 & 18.50 & 20.00 & 15.00 & 15.00 & 6.00 \\
\hline Median & 19.00 & 15.00 & 10.00 & 5.00 & 10.00 & 15.00 & 9.00 & 10.00 & 4.00 \\
\hline $\mathbf{1}^{\text {st }}$ quartile & 4.00 & 10.50 & 7.50 & 3.00 & 8.50 & 10.00 & 5.00 & 7.00 & 3.00 \\
\hline $\begin{array}{c}\text { Lower } \\
\text { whisker }\end{array}$ & 4.00 & 0.00 & 0.00 & 0.00 & 0.00 & 0.00 & 0.00 & 0.00 & 1.00 \\
\hline $\mathbf{N}$ & 103 & 103 & 103 & 103 & 103 & 103 & 103 & 103 & 103 \\
\hline
\end{tabular}

Source: self-edited

\subsection{Selection of Suitable Multivariate Regression Methods and Optimization Approaches}

The next step, after the successful collection of data, is to select the most suitable multivariate regression and optimization approach for the data and its conditions.

Optimization consists of two steps, the first being regression of data points on the input side. The second step is the actual optimization. Depending on the nature of the data and the underlying conditions, different regression approaches need to be evaluated for applicability. Nine different regression methods were selected for evaluation. The table below outlines the methods, a brief introduction and reason for selection or dismissal of the method. 
Table 2

Regression Method Selection

\begin{tabular}{ll}
\hline $\begin{array}{l}\text { Regression } \\
\text { Method }\end{array}$ & Description \\
\hline $\begin{array}{l}\text { Least } \\
\text { Square }\end{array}$ & $\begin{array}{l}\text { One of the oldest and most used regression } \\
\text { methods. Can be used when there is a linear } \\
\text { relationship between the dependent and } \\
\text { independent variables.[26]. }\end{array}$ \\
Partial & $\begin{array}{l}\text { This method uses the same approach as normal } \\
\text { least square method; it does not address the } \\
\text { original data, but uncorrelated variables } \\
\text { Square }\end{array}$ \\
$\begin{array}{l}\text { instead. The main advantage of this method } \\
\text { lies in the possibility to address multiple } \\
\text { output variables if necessary [27]. }\end{array}$ \\
$\begin{array}{l}\text { Polynomial method creates a polynomial function } \\
\text { Regression }\end{array}$ & $\begin{array}{l}\text { with the following structure [28]: } \\
p(x)=p_{1} x^{n}+p_{2} x^{-1}+\cdots+p_{n} x+p_{n+1}\end{array}$ \\
Logistic & $\begin{array}{l}\text { This method can be used if a categorical } \\
\text { output is available and to make the output } \\
\text { Regression } \\
\text { categories comparable with each other. This is } \\
\text { especially helpful if future predictions are } \\
\text { needed about how the input will be assigned to } \\
\text { a specific output category [29] }\end{array}$
\end{tabular}

Kernel This non-parametric method determines a Smoothing density function to forecast the probability at which input variables reside in a certain area. The advantage of this method is the capability to identify nonlinear relations between input and out variables [30].

Applicability for data set

Dismissed. Scatterplot analysis indicates a nonlinear nature of the data.

Dismissed. Multiple output variables are not needed.

Dismissed. Scatterplot analysis indicates a nonlinear behavior.

Dismissed. The output variable is a single value of the combined sum of project health factors. It is not a categorical output (like yes or no)

Dismissed. The goal of the regression step is to create an actual regression function suitable for optimization. Probabilities of input variable locations is not in focus.

Used. A second-degree polynomial regression function generates a satisfying result.

Dismissed. Increased complexity in this regression approach is not necessary as a suitable regression with 
Ridge Lasso Regression, it is. a selection-based

Regression regression method. In contrast to Lasso, ridge regression never sets the value of coefficients to absolute zero [32]. acceptable p-values result can be obtained with stepwise regression.

Dismissed. Not all coefficients are necessary.

Source: self-edited

After evaluating the different regression methods and selecting step-wise regression as the most applicable, a nonlinear optimization approach including additional constraints was chosen to identify a suitable maximum of combined project health factors in relation to the best distribution of project process relevance factors.

The Matlab solver fmincon, finds the minimum of a problem, with these constraints:

$$
\min _{x} f(x) \text { such that }\left\{\begin{aligned}
c(x) & \leq 0 \\
c e q(x) & =0 \\
A \cdot x & \leq b \\
A e q \cdot x & =b e q \\
l b & \leq x \leq u b
\end{aligned}\right.
$$

$b$ and $b e q$ are vectors, $A$ and Aeq are matrices, $c(x)$ and $c e q(x)$ are functions that return vectors, and $f(x)$ is a function that returns a scalar. $f(x), c(x)$, and $c e q(x)$ can be nonlinear functions [33].

For the optimization approach the following constraints were defined:

- The initial starting point for the iterative optimization method was defined as the average values of project process relevance's, ensuring that the result stays close to a common distribution defined by the survey participants.

- The sum of all project process relevance's needed to be $100 \%$.

- Upper and lower bounds of project process relevance's were defined with $+/-10 \%$ of the average values. This ensures that the optimization avoids extreme results, for example maximizing one project process to $100 \%$ and minimizing all other project process relevance's to $0 \%$.

- No linear inequality constraints were defined.

It has to be noted that the solver can only optimize through minimizing, so the reciprocal values of the output variable is used. 


\subsection{Regression including Fine Tuning}

After defining how to optimize the actual optimization in MATLAB, R2018a was performed including data cleaning. Based on the input data, an initial import to MS Excel was used, converting the textual structure of the raw data into table form suitable for MATLAB import. The result of this import can be seen as an example below in form of a table for the first 8 data sets.

It needs to be noted that the four project health factors were added up to a single output value, divided by 400 and then inverted and the reciprocal value taken to utilize the minimization solver of MATLAB for the maximization of project health.

Table 3

Example of 8 Data Sets after Data Cleaning in MS Excel

\begin{tabular}{|c|c|c|c|c|c|c|c|c|c|c|c|c|}
\hline 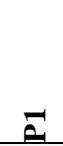 & $\hat{\Omega}$ & $\hat{\varepsilon}$ & $\Xi$ & $\stackrel{\leftrightarrow}{\varrho}$ & $\stackrel{0}{2}$ & $\underline{E}$ & $\stackrel{\infty}{\Perp}$ & 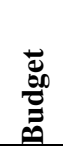 & 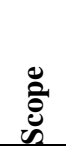 & 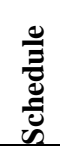 & 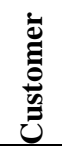 & Ë \\
\hline 14 & 20 & 18 & 14 & 28 & 1 & 3 & 2 & 19 & 21 & 14 & 23 & 0,8 \\
\hline 19 & 9 & 6 & 4 & 8 & 35 & 7 & 12 & 92 & 100 & 87 & 100 & 0,1 \\
\hline 14 & 20 & 18 & 14 & 28 & 1 & 3 & 2 & 19 & 21 & 14 & 23 & 0,8 \\
\hline 20 & 13 & 17 & 0 & 15 & 13 & 4 & 18 & 53 & 100 & 30 & 100 & 0,3 \\
\hline 45 & 10 & 10 & 10 & 10 & 5 & 5 & 5 & 100 & 80 & 80 & 90 & 0,1 \\
\hline 15 & 5 & 10 & 5 & 20 & 15 & 10 & 20 & 85 & 70 & 70 & 70 & 0,3 \\
\hline 24 & 15 & 12 & 11 & 20 & 11 & 0 & 7 & 88 & 52 & 61 & 77 & 0,3 \\
\hline 5 & 20 & 20 & 5 & 5 & 25 & 5 & 15 & 100 & 60 & 85 & 85 & 0,2 \\
\hline
\end{tabular}

Source: self-edited

After import of the cleaned data into MATLAB, the nonlinear stepwise regression approach second order was used to determine a suitable regression function:

> mdl=stepwiselm(Input,Output,'poly22222222')

Where:

Input $=$ the input matrix of process 1 to 8

Output $=$ the single column output matrix

As a result of this regression, MATLAB estimates these coefficients and statistical values for the regress function:

The $\mathrm{p}$-values of the sixth process $\mathrm{x} 6$ and the combined factor $\mathrm{x} 2 * \mathrm{x} 8$ are too high based on the $5 \%$ proposed p-value cutoff [34] with values of $13 \%$ and $8 \%$. This indicates that there might be a critical collinearity of the sixth process in 
relation to the output. Therefore, an additional correlation matrix was developed to ensure that all the processes are within acceptable correlation boundaries regarding correlation.

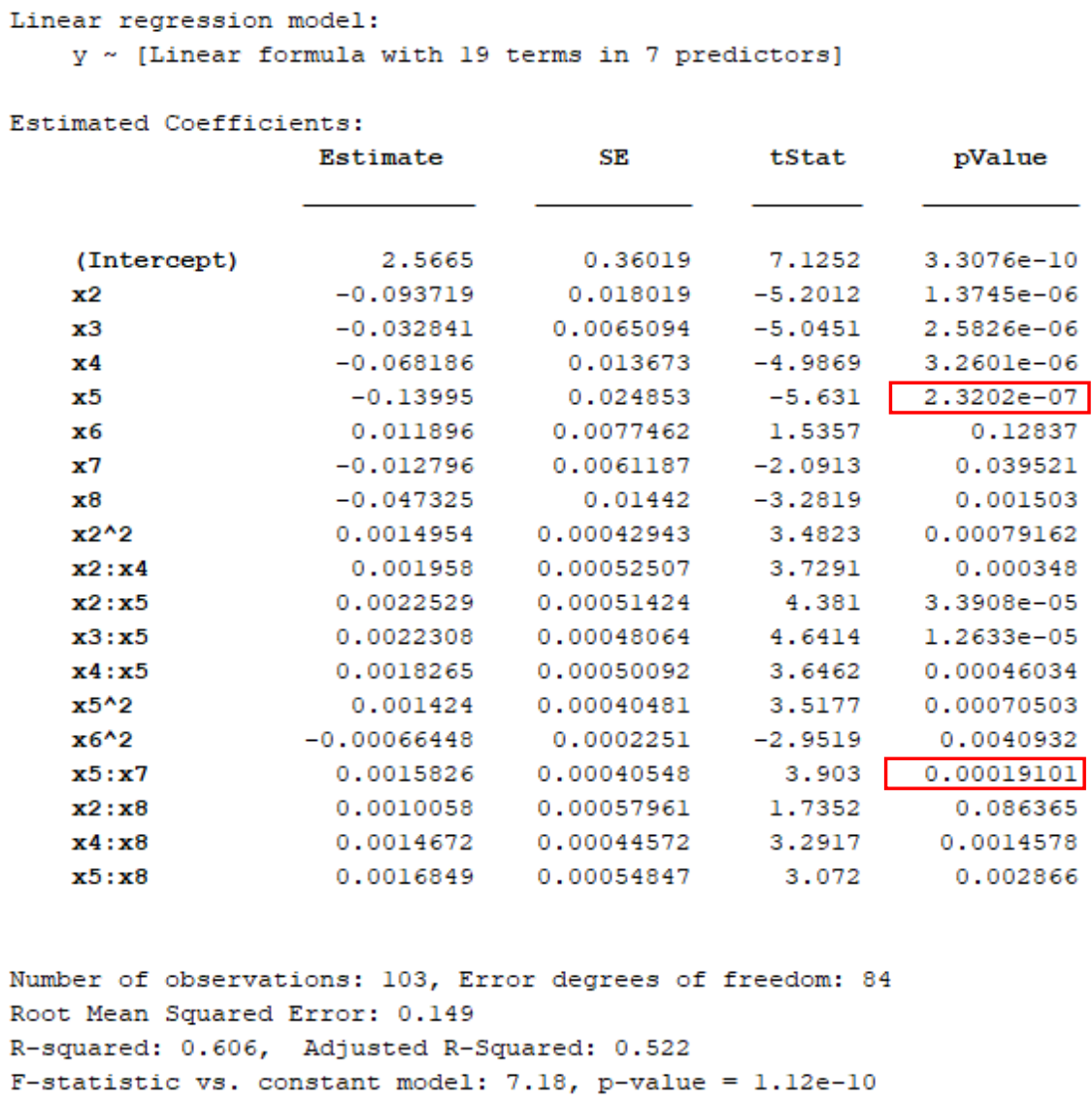

Figure 2

Project Regression Result

Source: self-edited

As highlighted with red boxes in figure 3, the process 6, Manage Communications, indicates a high p-value with 0.128, above 0.05 nonsignificance. Consequently, the influence of the P6 process on the overall model needs to be investigated in detail.

The correlation matrix in table 4 shows that the absolute value of Pearson correlation coefficient is with a maximum of 0.36 less than 0.8 , so multicollinearity is less likely to exist [35]. 
Table 4

Correlation Matrix with all Variables

\begin{tabular}{|c|c|c|c|c|c|c|c|c|c|}
\hline & & P1 & $\mathrm{P} 2$ & P3 & $\mathrm{P} 4$ & P5 & P6 & P7 & P8 \\
\hline \multirow[t]{3}{*}{$\mathrm{P} 2$} & Correlation & -0.128 & & & & & & & \\
\hline & Significance & 0.240 & & & & & & & \\
\hline & $\mathrm{N}$ & 86 & & & & & & & \\
\hline \multirow[t]{3}{*}{ P3 } & Correlation & 0.020 & 0.005 & & & & & & \\
\hline & Significance & 0.858 & 0.967 & & & & & & \\
\hline & $\mathrm{N}$ & 86 & 86 & & & & & & \\
\hline \multirow[t]{3}{*}{$\mathrm{P} 4$} & Correlation & $-0.356^{* *}$ & -0.003 & 0.057 & & & & & \\
\hline & Significance & 0.001 & 0.979 & 0.605 & & & & & \\
\hline & $\mathrm{N}$ & 86 & 86 & 86 & & & & & \\
\hline \multirow[t]{3}{*}{ P5 } & Correlation & $-0.322 * *$ & -0.211 & -0.083 & $0.291 * *$ & & & & \\
\hline & Significance & 0.002 & 0.051 & 0.449 & 0.007 & & & & \\
\hline & $\mathrm{N}$ & 86 & 86 & 86 & 86 & & & & \\
\hline \multirow[t]{3}{*}{ P6 } & Correlation & -0.043 & $-0.309^{* *}$ & $-0.288 * *$ & $-0.360 * *$ & $-0.298 * *$ & & & \\
\hline & Significance & 0.696 & 0.004 & 0.007 & 0.001 & 0.005 & & & \\
\hline & $\mathrm{N}$ & 86 & 86 & 86 & 86 & 86 & & & \\
\hline \multirow[t]{3}{*}{ P7 } & Correlation & $-0.243^{*}$ & 0.019 & $-0.270 *$ & -0.123 & -0.159 & -0.136 & & \\
\hline & Significance & 0.024 & 0.861 & 0.012 & 0.261 & 0.144 & 0.212 & & \\
\hline & $\mathrm{N}$ & 86 & 86 & 86 & 86 & 86 & 86 & & \\
\hline \multirow[t]{3}{*}{ P8 } & Correlation & $-0.254 *$ & -0.114 & $-0.284 * *$ & $-0.340 * *$ & -0.202 & 0.136 & 0.127 & \\
\hline & Significance & 0.018 & 0.298 & 0.008 & 0.001 & 0.062 & 0.212 & 0.244 & \\
\hline & $\mathrm{N}$ & 86 & 86 & 86 & 86 & 86 & 86 & 86 & \\
\hline \multirow[t]{3}{*}{ Output } & Correlation & 0.022 & $-0.291 * *$ & 0.111 & -0.112 & -0.208 & $0.357 * *$ & -0.125 & 0.137 \\
\hline & Significance & 0.837 & 0.007 & 0.308 & 0.303 & 0.055 & 0.001 & 0.252 & 0.207 \\
\hline & $\mathrm{N}$ & 86 & 86 & 86 & 86 & 86 & 86 & 86 & 86 \\
\hline \multicolumn{10}{|c|}{$* * \mathrm{p}<0.01$ (two-tailed) } \\
\hline$<0$ & (two-tailed) & & & & & & & & \\
\hline
\end{tabular}

Source: self-edited

Keeping the critical process P6 static, the partial correlation matrix in table 5 also indicates no critical collinearity between the other input variables and the output variable.

Table 5

Partial Correlation with P6 as Control Variable

\begin{tabular}{|l|c|c|l|l|l|l|l|l|l|}
\hline \multicolumn{2}{|c|}{} & \multicolumn{1}{|c|}{ P1 } & P2 & P3 & P4 & P5 & P7 & P8 \\
\hline \multirow{7}{*}{ P6 } & P2 & Correlation & -0.149 & & & & & & \\
\hline & Significance & 0.174 & & & & & & \\
\hline & $\begin{array}{c}\text { Degrees of } \\
\text { freedom }\end{array}$ & 83 & & & & & & \\
\cline { 3 - 10 } & P3 & Correlation & 0.008 & -0.093 & & & & & \\
\cline { 3 - 10 } & Significance & 0.945 & 0.398 & & & & & \\
\hline & Degrees of & 83 & 83 & & & & & \\
\hline
\end{tabular}




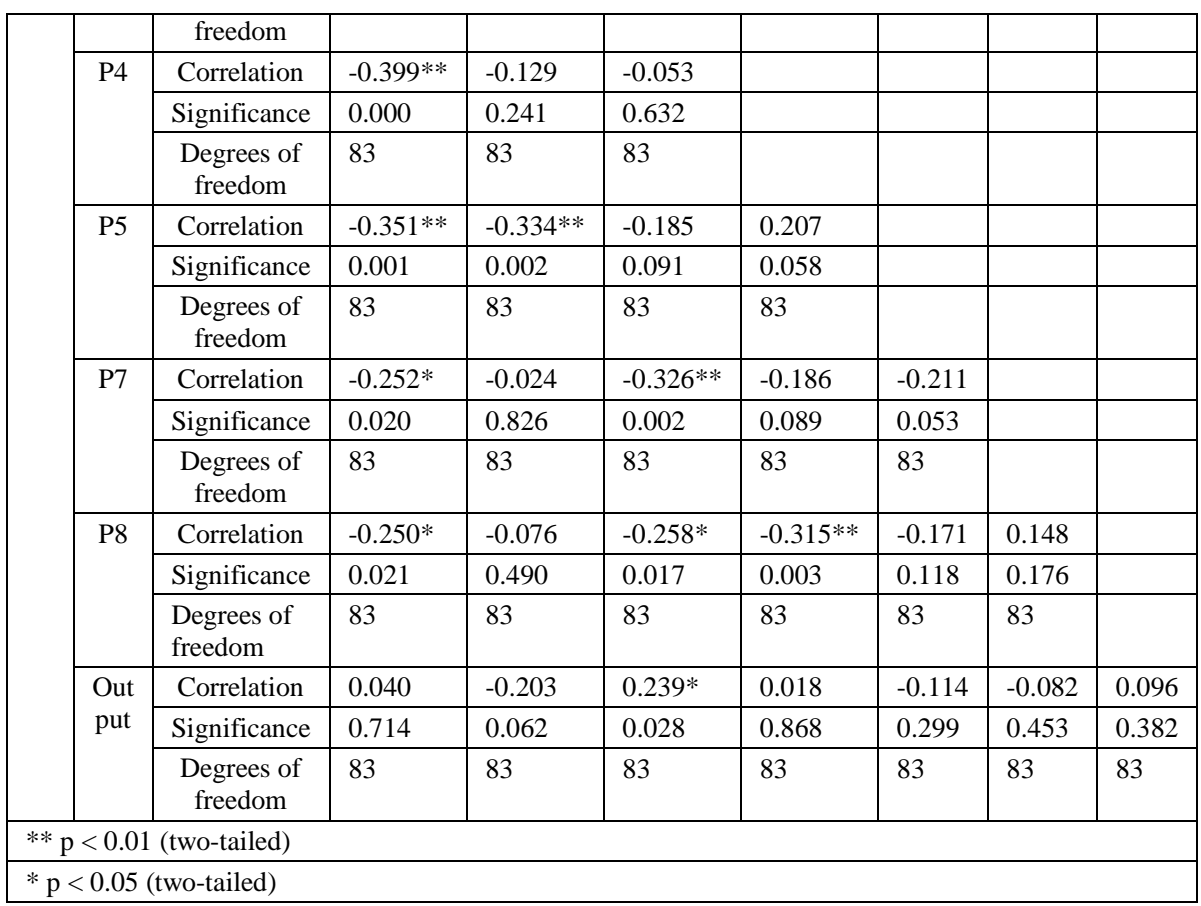

Source: self-edited

It can be concluded, that the high p-values may not be critical in regards to the validity of the regression model. In the case combining $\mathrm{x} 2$ and $\mathrm{x} 8$ factors, the significance level is with 0.086 not as critical as the previously proven uncritical P6 process. For further analysis, the model is accepted as the basis for optimization even at this significance level.

\subsection{Optimization of Process Relevance Factors}

As a last step, the polynomial regression function is maximized under certain boundaries and conditions to propose an optimum distribution of project process relevance factors.

Using the developed regression coefficients, the following regression function is defined as:

fun=@(x)+2.5665-0.093719*x(2)-0.032841*x(3)-0.068186*x(4)-

$0.13995 * \mathrm{x}(5)+0.011896 * \mathrm{x}(6)-0.012796 * \mathrm{x}(7)-$

$0.047325 * \mathrm{x}(8)+0.0014954 * \mathrm{x}(2)^{\wedge} 2+0.001958 * \mathrm{x}(2) * \mathrm{x}(4)+0.0022529 * \mathrm{x}(2$

)$^{*} \mathrm{x}(5)+0.0022308 * \mathrm{x}(3) * \mathrm{x}(5)+0.0018265 * \mathrm{x}(4) * \mathrm{x}(5)+0.001424 * \mathrm{x}(5) \wedge 2-$

$0.00066448 * \mathrm{x}(6)^{\wedge} 2+0.0015826 * \mathrm{x}(5) * \mathrm{x}(7)+0.0010058 * \mathrm{x}(2) * \mathrm{x}(8)+0.001$

$4672 * \mathrm{x}(4) * \mathrm{x}(8)+0.0016849 * \mathrm{x}(5) * \mathrm{x}(8)$ 
As initial starting point for the optimization, the average project process relevance factors are used:

$x 0=[18.9 ; 14.7 ; 11.1 ; 7.1 ; 12.9 ; 14.7 ; 9.3 ; 11.2]$

The constraint effecting that all input variables add up to 100 is defined as such:

$A e q=\left[\begin{array}{llllllll}1 & 1 & 1 & 1 & 1 & 1 & 1 & 1\end{array}\right]$

beq $=[100]$

The constraint defining the upper and lower bounds of the process relevance factors with $+/-10 \%$ of the average value is defined as such:

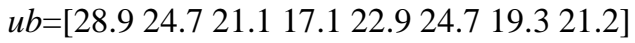

$l b=\left[\begin{array}{llllllll}8.9 & 4.7 & 1.1 & 0 & 2.9 & 4.7 & 0 & 1.2\end{array}\right]$

Linear inequality constraints are defined as such:

$A=[]$

$b=[]$

The optimization solver $\mathrm{x}=\mathrm{fmincon}(\mathrm{fun}, \mathrm{x} 0, \mathrm{~A}, \mathrm{~b}, \mathrm{Aeq}, \mathrm{beq}, \mathrm{lb}, \mathrm{ub}$ ) uses a sequential quadratic programming method [36] [37] and generates a suitable optimization result.

\section{Results and Discussion}

As the overall result of the optimization phase, it can be concluded that the best distribution of project process relevance factors for the defined scope and boundaries based on the currently collected data looks as such:

Table 6

Result of Optimization

\begin{tabular}{|c|c|}
\hline Project Process & Optimized Project Process Relevance \\
\hline P1: Direct and Manage Project Work & $28.3 \%$ \\
\hline P2: Manage Project Knowledge & $4.7 \%$ \\
\hline P3: Manage Quality & $1.1 \%$ \\
\hline P4: Develop Team & $17.1 \%$ \\
\hline P5: Manage Team & $22.9 \%$ \\
\hline P6: Manage Communications & $24.7 \%$ \\
\hline P7: Implement Risk Responses & $0 \%$ \\
\hline P8: Manage Stakeholder Engagement & $1.2 \%$ \\
\hline
\end{tabular}


Interpreting the results, it is clearly obvious that defining the upper and lower boundaries as constraints has a large influence on the optimization value. All final values, except the Process Direct and Manage Project Work, which is only 0.6\% below the upper bounder, are situated either in an upper or lower boundary. This indicates that the optimization step would bring some project processes to zero and continue maximizing other project processes even more. To get a better understanding of these trends, it is helpful to repeat the optimization without upper and lower boundaries.

Table 7 shows that the optimization without boundaries maximizes only two project processes and sets all other project processes to $0 \%$. This approach suggests putting $87.5 \%$ of focus or relevance on the process of Manage Communications. Naturally, these values are far from realistic and usable. Yet, however they can visualize the importance of Communication for project success [38].

It is obvious that the selected boundaries of $+/-10 \%$ of the average value are open for discussion or change. These boundaries can also be seen as a damper protecting the optimization from being too radical and therefore proposing unrealistic values to project managers.

Table 7

Result of Optimization Considering Boundaries

\begin{tabular}{lcc}
\hline Project Process & $\begin{array}{c}\text { Optimized Project } \\
\text { Process Relevance } \\
\text { with Upper and } \\
\text { Lower Boundaries }\end{array}$ & $\begin{array}{c}\text { Optimized Project } \\
\text { Process Relevance } \\
\text { without Upper and } \\
\text { Lower Boundaries }\end{array}$ \\
\hline Direct and Manage Project Work & $28.3 \%$ & $0 \%$ \\
Manage Project Knowledge & $4.7 \%$ & $0 \%$ \\
Manage Quality & $1.1 \%$ & $0 \%$ \\
Develop Team & $17.1 \%$ & $0 \%$ \\
Manage Team & $22.9 \%$ & $12.5 \%$ \\
Manage Communications & $24.7 \%$ & $87.5 \%$ \\
Implement Risk Responses & $0 \%$ & $0 \%$ \\
Manage Stakeholder Engagement & $1.2 \%$ & $0 \%$ \\
\hline
\end{tabular}

Source: self-edited

With regard to the general overview, the following description of the individual processes can be presented: 
Direct and Manage Project Work is the process of actually implementing and doing the work defined in the project plan [39]. In the boundary restricted result this process shows the highest relevance with $28.3 \%$, indicating that a lot of successful project managers put much focus and effort in this project process.

Manage Communications has the second highest relevance with $24.7 \%$. Looking at the unconstrained optimization, the relevance even increases to $87.5 \%$. This indicates high relevance of communication for project health in the execution phase of projects. The importance of successful communication as critical factor for project success is also a widespread result in project management research. [40] [41] [42]

Manage Team is the process of tracking and optimizing the project team performance. With $22.9 \%$, this process shows a high relevance in the work of successful project managers.

Developing the team by improving competences and interaction is also of high importance for project success [43]. The value of $17.1 \%$ is the defined upper boundary of the optimization. However, without boundaries, the process moves towards zero due to increasing importance of the project process Manage Communications.

To sum up the project processes Manage Project Knowledge, Manage Quality, Implement Risk Responses and Manage Stakeholder Engagement it can be said that they show low relevance in the optimized relevance distribution. Explaining this behavior is not within the scope of this research yet. As a hypothesis, it can be suggested that a healthy project needs less of the troubleshooting-oriented project processes, like managing quality, risks, engagement and knowledge about the project. One could argue that a project manager can move towards a positive circle within the project. So, if he or she is not busy implementing risk responses for example, more time for communication, managing the team and the project work can keep the project healthy and successful.

\section{Conclusions}

The goal of this research was to show that multivariate optimization methods can be applied, for proposing optimized work flow processes, for project managers. This approach can reduce the tendency of the project management profession of being subjective, individualistic and hard to capture. Each and every project is unique, and it is a highly important competence, for project managers, to adapt and react in a flexible way, with the different challenges, that occur in the daily work of project management. It has to be noted, that this research does not suggest following the optimized relevance factors exactly. Knowing about an optimized distribution, based on data and not on subjective interpretations and recommendations, could help to highlight how successful project managers do their work and therefore, act as guides for all other project management 
practitioners. The result of this research is a proof of concept, showing the potential of an optimization approach and the challenges involved in using constraints, to adapt unrealistic results, if needed.

Several limitations need to be mentioned in order to prevent potential misinterpretation. The most important factor is the relatively small set of heterogenic survey participants and the resulting data. For more reliable results, the additional project and personal characteristics should be used to filter and preselect data sets for optimization. In order to create a reliable result, for example, only small, agile developed projects, in the financial industry, managed by less-experienced project managers, might be selected. With such specific selection of categories, many additional aspects and insights could emerge from the data, after optimization.

Another limitation that should be mentioned is the fact that many survey participants learned about this research and gave their input during the flow of their projects. There was no phase of introduction about this research from the beginning of their project onwards. Knowing in advance that project process relevance is in focus and measured by a survey application, could lead to less subjective values, increasing the overall quality of the data.

Last but not least, a gap in the nature of input and output variables needs to be mentioned. The project health factors are overall values, which are valid for all project phases from the start. Therefore, positive project health could already be transmitted into other project phases. The survey on the input side completely focusses on the execution phase, not considering results of previous phases. This additional influence on the output factors, which overlap with project phases, reduces the significance of the optimization result.

\section{Perspectives for Future Research}

To tackle the mentioned limitation and increase the reliability of the data and the optimization result [13], several improvements are planned for future research.

One approach is the automation of data collection. To reduce the subjective human factor, additional data sources can be used [44], like measured times in certain software programs. For example, the screen time could be measured with MS Project and connected to project plan-related project processes, at least giving survey participants the change to categorize activities on a daily basis. Like not collecting data once per participant, but ongoing, over the whole project. Simply adding the possibility of categorizing meetings in regards to project processes directly in outlook would increase the quality of data drastically.

Another approach, to reduce the subjective nature of the result, is to shorten the research phase in the project. Especially agile frameworks, like SCRUM are perfect candidates for such measures, due to their iterative nature. Thus, a next step could be moving away from PMBOK project processes, towards activities and tasks during sprints. Using the proof of concept of this research as a guideline, 
optimizing the work in sprints for the different roles in traditional SCRUM based organizations could be a useful goal for further research activities.

\section{References}

[1] Project Management Institute: A Guide to the Project Management Body of Knowledge (PMBOK guide) Newtown Square, Pennsylvania: Project Management Institute, 2017

[2] Dittmann K.; Dirbanis K.: Projektmanagement (IPMA®): Lehrbuch für Level D und Basiszertifikat (GPM) $1^{\text {st }}$ ed. Freiburg: Haufe Group, 2021

[3] AXELOS Limited: Managing successful projects with PRINCE2®. 2017th ed. London: TSO, 2017

[4] Rainer Wendt: Hybrides Projektmanagement für agile Projekte in mittelständischen und großen Unternehmen. PMI Southern Germany Chapter 2016, 12-2016.p.

[5] Pichler R.: Scrum: Agiles Projektmanagement erfolgreich einsetzen. $1^{\text {st }}$ ed. Heidelberg: dpunkt.verlag, 2013

[6] Shane Hastie: Chaos Report (2015) Available at: https://www.infoq.com/articles/standish-chaos-2015, Accessed Oct 18, 2021

[7] Kukushkin A.; Zykov S.: The Dynamic Modeling of the Project Management Process. Procedia Technology, 9 2013, pp. 893-899, doi:10.1016/j.protcy.2013.12.099

[8] Márta Takács: Multilevel Fuzzy Approach to the Risk and Disaster Management. Acta Polytechnica Hungarica, 2010 (7) 2010, pp. 91-102

[9] Ferenc Bognár: A Novel Risk Assessment Methodology - A Case Study of the PRISM Methodology in a Compliance Management Sensitive Sector. Acta Polytechnica Hungarica, 2021 (18) 2021, pp. 89-108

[10] van der Aalst; Wil M. P. et al.: Business Process Management. Bus Inf Syst Eng, 58 (1) 2016, pp. 1-6, doi:10.1007/s12599-015-0409-x

[11] vom Brocke J.; Rosemann M.: Handbook on Business Process Management 2, Berlin, Heidelberg: Springer Berlin Heidelberg, 2010

[12] Sonteya T.; F Seymour L.: Towards an Understanding of the Business Process Analyst: An Analysis of Competencies. JITE:Research, 11 2012, pp. 43-63, doi:10.28945/1568

[13] János Varga; Ágnes Csiszárik-Kocsir: Redefining the Role of Project Leader for Achieving a Better Project Result. In: PM World Journal, pp. 118 
[14] Khuri A. I.; Conlon M.: Simultaneous Optimization of Multiple Responses Represented by Polynomial Regression Functions. Technometrics, 23 (4) 1981, pp. 363-375, doi:10.1080/00401706.1981.10487681

[15] Gauri S. K.; Pal S.: Comparison of performances of five prospective approaches for the multi-response optimization. Int J Adv Manuf Technol, 48 (9-12) 2010, pp. 1205-1220, doi:10.1007/s00170-009-2352-9

[16] Del Castillo E.; Montgomery D. C.: A Nonlinear Programming Solution to the Dual Response Problem. Journal of Quality Technology, 25 (3) 1993, pp. 199-204, doi:10.1080/00224065.1993.11979454

[17] Wagner E.: Projektmanagement-Zertifizierungen im Vergleich. Projektmagazin 2019, 12 June 2019, Available at: https://www.projektmagazin.de/artikel/projektmanagementzertifizierungen-vergleich. Accessed Oct 18, 2021

[18] Matos S.; Lopes E.: Prince2 or PMBOK - A Question of Choice. Procedia Technology, 9 2013, pp. 787-794, doi:10.1016/j.protcy.2013.12.087

[19] György Kadocsa: Research of Competitiveness Factors of SME. Acta Polytechnica Hungarica, 2006 (3) 2006, pp. 71-84

[20] ProjectEngineer: The PMBOK's Five Project Phases. Available at: https://www.projectengineer.net/the-pmboks-five-project-phases/. Accessed October 18, 2021

[21] Atkinson R.: Project management: cost, time and quality, two best guesses and a phenomenon, its time to accept other success criteria. International Journal of Project Management, 17 (6) 1999, pp. 337-342, doi:10.1016/S0263-7863(98)00069-6

[22] van Wyngaard C. J. et al.: Strategic management of the triple constraint trade-off dynamics - a polarity management approach. In: IEEE International Conference on Industrial Engineering and Engineering Management (IEEM), 2011: 6-9 Dec. 2011, Singapore. Piscataway, NJ: IEEE, 2011, pp. 824-828

[23] Cloud Application Platform - Heroku. Available at: https://www.heroku.com/. Accessed Oct 18, 2021

[24] Ashmore S.; Runyan K.: Introduction to agile methods. Upper Saddle River, NJ, Munich: Addison-Wesley, 2015

[25] Tolbert M.; Parente S.: Hybrid project management: Using agile with traditional PM methodologies to succeed on modern projects. $2020^{\text {th }}$ ed. New York: BEP, 2020

[26] Fahrmeir L. et al.: Regression: Modelle, Methoden und Anwendungen. $2^{\text {nd }}$ ed. Berlin, Heidelberg: Springer Berlin Heidelberg, 2009 
[27] Geladi P.; Kowalski B. R.: Partial least-squares regression: a tutorial. Analytica Chimica Acta, 185 1986, pp. 1-17, doi:10.1016/00032670(86)80028-9

[28] Ostertagová E.: Modelling using Polynomial Regression. Procedia Engineering, 48 2012, pp. 500-506, doi:10.1016/j.proeng.2012.09.545

[29] Kleinbaum D. G.; Klein M.: Logistic regression: A self-learning text. New York, Dordrecht, Heidelberg, London: Springer, 2010

[30] O’Brien C. M.: Smoothing Splines: Methods and Applications by Yuedong Wang. International Statistical Review, 80 (3) 2012, pp. 475-476, doi:10.1111/j.1751-5823.2012.00196_6.x

[31] Ranstam J.; Cook J. A.: LASSO regression. British Journal of Surgery, 105 (10) 2018, 1348. p. doi:10.1002/bjs.10895

[32] McDonald G. C.: Ridge regression. WIREs Comp Stat, 1 (1) 2009, pp. 93100, doi:10.1002/wics.14

[33] Find minimum of constrained nonlinear multivariable function - MATLAB fmincon. Available at: https://www.mathworks.com/help/optim/ug/ fmincon.html. Accessed October 18, 2021

[34] Altman N.; Krzywinski M.: Interpreting P values. Nat Methods, 14 (3) 2017, pp. 213-214, doi:10.1038/nmeth.4210.

[35] Young D. S.: Handbook of regression methods. Boca Raton, FL, London, New York: CRC Press Taylor \& Francis Group, 2017

[36] Fletcher R.; Powell M. J. D.: A Rapidly Convergent Descent Method for Minimization. The Computer Journal, 6 (2) 1963, pp. 163-168, doi:10.1093/comjnl/6.2.163

[37] Goldfarb D.: A family of variable-metric methods derived by variational means. Math. Comp., 24 (109) 1970, pp. 23-26, doi:10.1090/S0025-57181970-0258249-6

[38] Zulch B. G.: Communication: The Foundation of Project Management. Procedia Technology, 16 2014, pp. 1000-1009

[39] Sanghera P.: Monitoring and Controlling the Project Work. In: PMP® in Depth: Project Management Professional Certification Study Guide for the PMP® Exam (Editor: P. Sanghera). Berkeley, CA: Apress L. P, 2018, pp. 439-478

[40] Doloi H.: Relational partnerships: the importance of communication, trust and confidence and joint risk management in achieving project success. Construction Management and Economics, 27 (11) 2009, pp. 1099-1109

[41] Ramsing L.: Project communication in a strategic internal perspective. Corp Comm: An Int Jnl, 14 (3) 2009, pp. 345-357 
[42] Lievens A.; Moenaert R. K.: Project Team Communication in Financial Service Innovation. J Management Studs, 37 (5) 2000, pp. 733-766

[43] Assaf S. et al.: Effectiveness of Project Teams and their Impact on the Performance of Saudi Construction Projects. RJASET, 7 (24) 2014, pp. 5148-5156, doi:10.19026/rjaset.7.911

[44] Shukla R. K. et al.: Comparison of subjective versus data base approaches for improving efficiency of operating room scheduling. Health Serv Manage Res, 3 (2) 1990, pp. 74-81, doi:10.1177/095148489000300201 